\title{
Surface Chemistry of Almandine Garnet
}

Jeffrey Poon ${ }^{1}$, David C. Madden ${ }^{1}$, Mary H. Wood ${ }^{1 \#}$, Ron van Tol ${ }^{2}$, Hans Sonke ${ }^{2}$, and Stuart M. Clarke ${ }^{* 1}$

${ }^{1}$ BP Institute and Department of Chemistry, University of Cambridge, Cambridge UK, CB3 OEZ

${ }^{2}$ Shell Global Research Centre, Amsterdam, The Netherlands

\# Present address: School of Chemistry, University of Birmingham, Birmingham, B15 2TT

* Corresponding author: stuart@bpi.cam.ac.uk; +00 44 (0) 1223765700

\section{Supporting Information}

Table S1: Quoted Composition of the Almandine Garnet ('Garnet') Abrasive

\begin{tabular}{|c|c|c|}
\hline Mineral Name & Formula & Percentage Composition \\
\hline Almandine garnet & $\mathrm{Fe}_{3} \mathrm{Al}_{2}\left(\mathrm{SiO}_{4}\right)_{3}$ & $>97 \%$ \\
\hline Ilmenite & $\mathrm{FeTiO}_{3}$ & $<1.5 \%$ \\
\hline Calcium Carbonate & $\mathrm{CaCO}_{3}$ & $<1.5 \%$ \\
\hline Zircon & $\mathrm{ZrSiO}_{4}$ & $<0.2 \%$ \\
\hline Quartz & $\mathrm{SiO}_{2}$ & $<0.5 \%$ \\
\hline
\end{tabular}

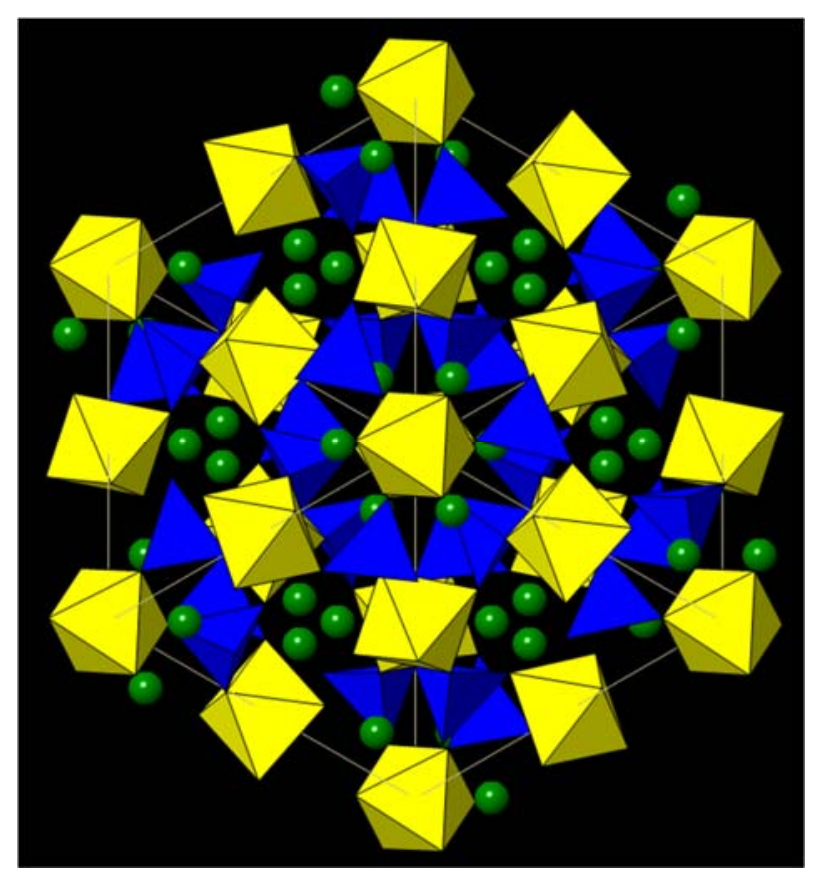

Figure S1: A unit cell of the almandine garnet crystal structure in polyhedral representation. Yellow octahedra are $\left\{\mathrm{AlO}_{6}\right\}$ units, and blue tetrahedra are $\left\{\mathrm{SiO}_{4}\right\}$ units. Green atoms are Fe, residing in large 'voids' within the octahedral-tetrahedral framework. 

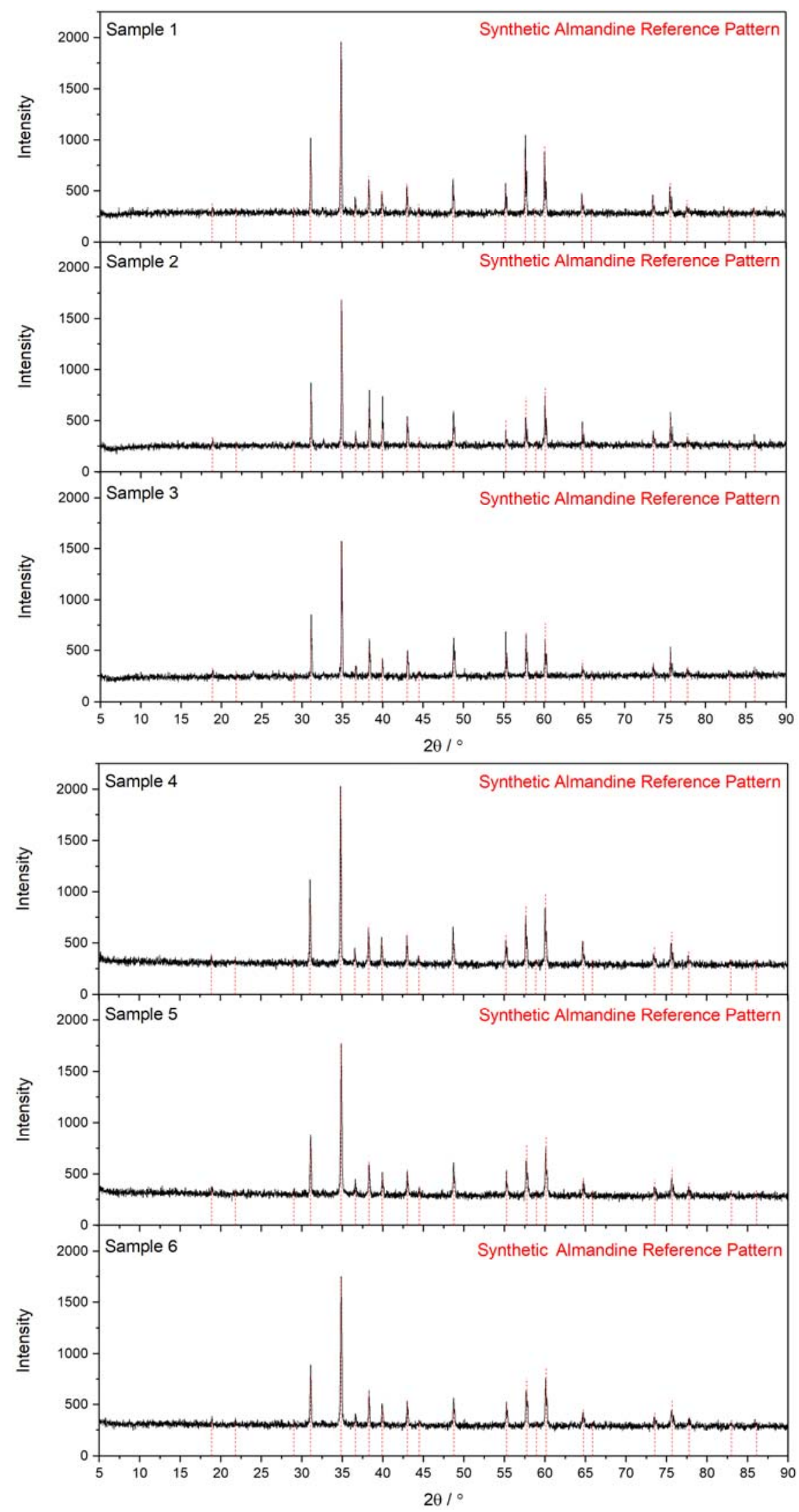

Figure S2: Powder X-ray diffraction data of almandine garnet before (samples 1-3) and after (samples 4-6) acid washing. The powders were tumbled for one week in $0.1 \mathrm{M} \mathrm{HCl}$ (samples 1 and 4), ultrapure water (samples 2 and 5) or $0.1 \mathrm{M} \mathrm{NaOH}$ (samples 3 and 6); all show good agreement with the reference 
almandine garnet spectrum (from American Mineralogist (1992) 77 (5-6) 512-521)), the peaks from which are indicated by the red dotted lines.
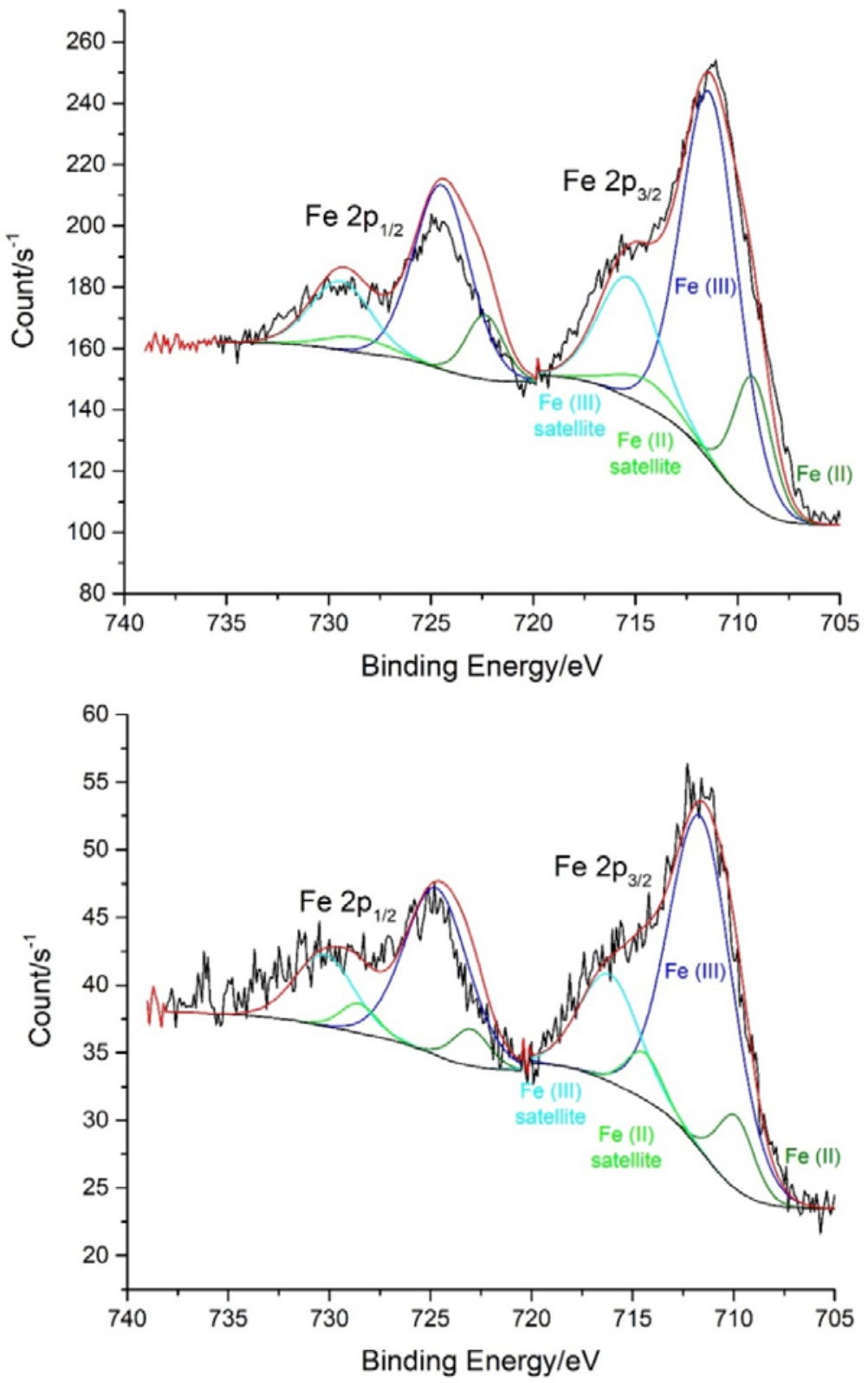

\begin{tabular}{|c|c|c|c|c|c|}
\hline \multirow{2}{*}{\multicolumn{2}{|c|}{ Fe $2 p$}} & \multicolumn{2}{|c|}{ Fe (II) } & \multicolumn{2}{|c|}{$\mathrm{Fe}(\mathrm{III})$} \\
\hline & & $2 p_{3 / 2}$ & $2 p_{1 / 2}$ & $2 p_{3 / 2}$ & $2 p_{1 / 2}$ \\
\hline \multicolumn{2}{|c|}{ Position / eV } & 709.27 & 722.37 & 711.37 & 724.47 \\
\hline \multirow{2}{*}{$\begin{array}{l}\text { Full Width Half } \\
\text { Maximum / eV }\end{array}$} & $22.5^{\circ}$ & 2.14 & 2.14 & 3.23 & 3.23 \\
\hline & $77.5^{\circ}$ & 2.14 & 2.14 & 3.70 & 3.70 \\
\hline \multirow{2}{*}{$\%$ Area } & $22.5^{\circ}$ & \multicolumn{2}{|c|}{19} & \multicolumn{2}{|c|}{81} \\
\hline & $77.5^{\circ}$ & \multicolumn{2}{|c|}{14} & \multicolumn{2}{|c|}{86} \\
\hline
\end{tabular}

Figure S3: AR-XP spectra for the Fe $2 p$ region at $0^{\circ}$ (top) and $50^{\circ}$ (bottom) surveying angles to the surface normal, varied by stage tilt, and the corresponding peak fitting results. 


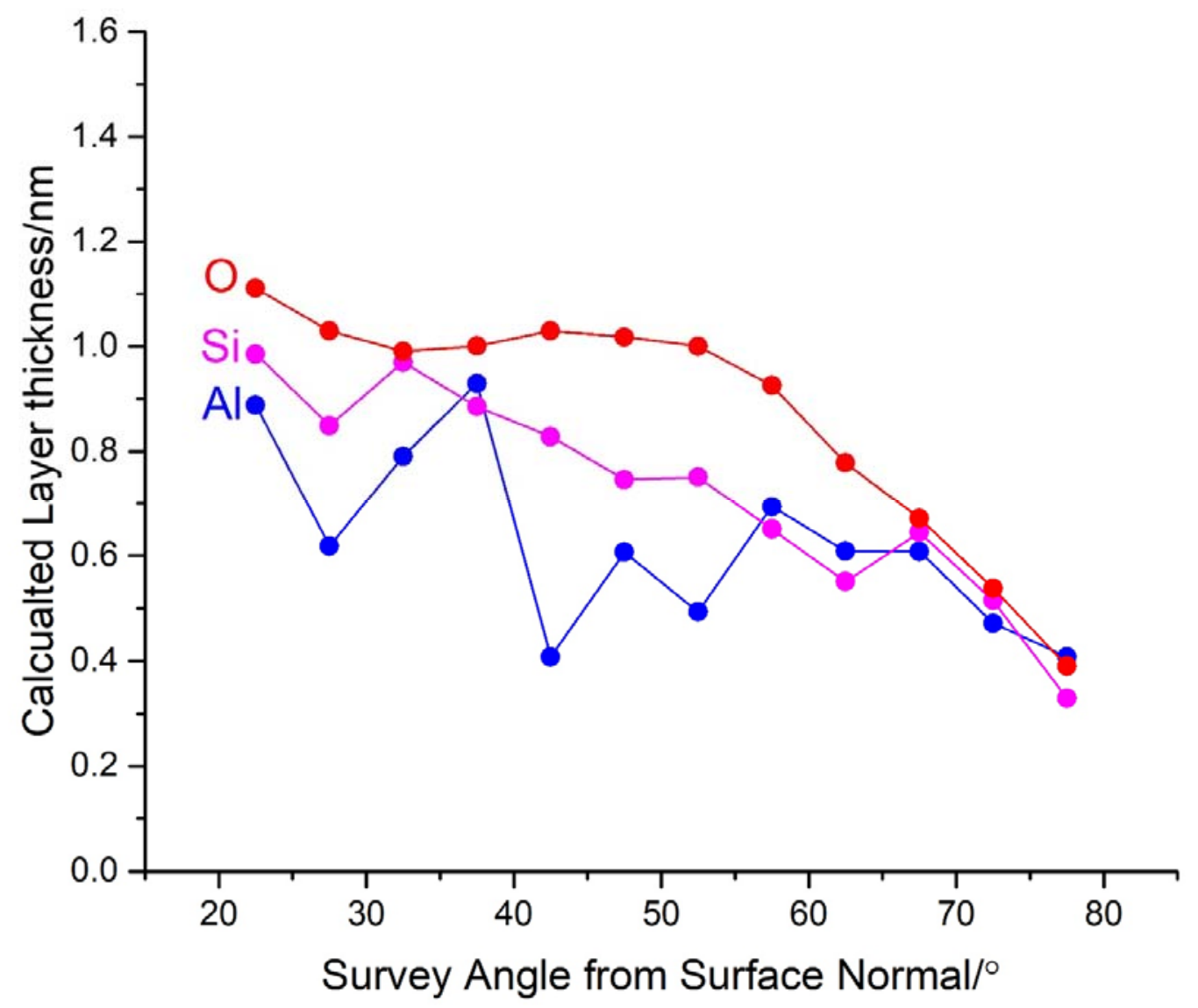

Figure S4: Surface layer thicknesses calculated from AR-XP spectra at different surveying angles for Al, Si and 0 , using the method discussed in the main text.

Table S2: ICP-OES Results Indicating the Dissolved Fe, Al, and Si in the Supernatant after Tumbling $4 \mathrm{~g}$ AcidWashed Garnet Powder in $20 \mathrm{~mL}$ of the Liquid Indicated for One Week (the solids removed were studied with PXRD: these are samples 4-6, shown in Figure S2)

The dissolved concentrations are also converted to estimate the percentage of the atoms initially present in the garnet powder that are dissolved, and the numbers of atoms dissolved per unit area of the solid surface (using the measured specific surface area of the acid-washed garnet powder, $5.54 \mathrm{~m}^{2} \mathrm{~g}^{-1}$ ).

\begin{tabular}{|l|l|l|l|l|l|l|l|l|l|l|}
\cline { 2 - 11 } & \multicolumn{4}{l|}{$\begin{array}{l}\text { dissolved concentration } \\
\text { / } \mathbf{~ m M ~}\end{array}$} & \multicolumn{3}{l|}{$\begin{array}{l}\text { \% of atoms initially } \\
\text { present dissolved }\end{array}$} & \multicolumn{3}{l|}{$\begin{array}{l}\text { dissolved atoms from } \\
\text { surface / } \mathbf{~ m}^{-2}\end{array}$} \\
\cline { 2 - 12 } & Fe & Al & Si & Fe & Al & Si & Fe & Al & Si \\
\hline $\mathbf{0 . 1} \mathbf{~ M ~ H C l}$ & 4.161 & 4.050 & 4.840 & 0.3452 & 0.5040 & 0.4016 & 2.262 & 2.201 & 2.631 \\
\hline ultrapure water & 0.005 & 0.004 & 0.627 & 0.0004 & 0.0006 & 0.0521 & 0.003 & 0.002 & 0.341 \\
\hline $\mathbf{0 . 1} \mathbf{~ M ~ N a O H}$ & 0.018 & 0.608 & 17.846 & 0.0015 & 0.0757 & 1.4805 & 0.010 & 0.330 & 9.699 \\
\hline
\end{tabular}




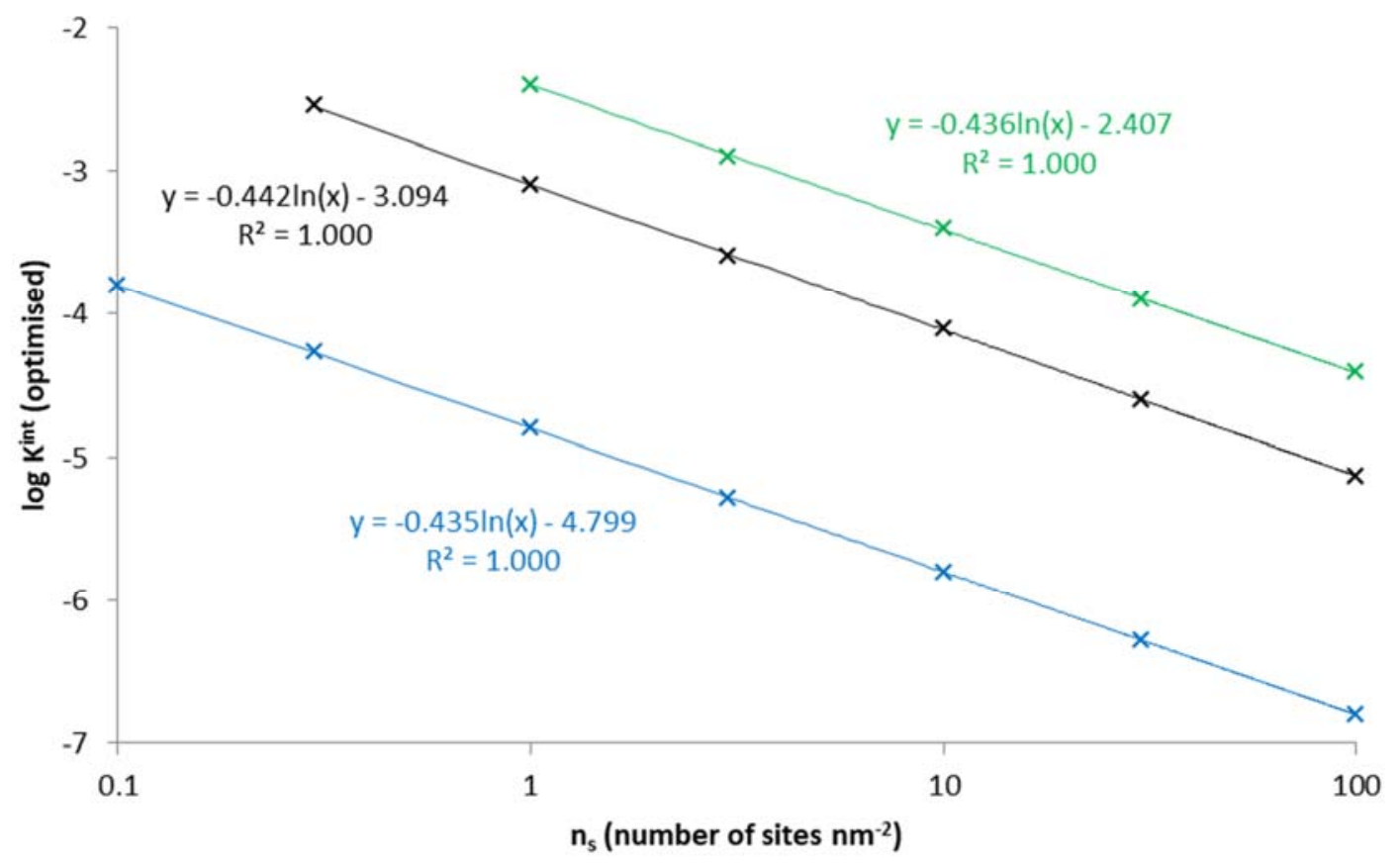

Figure S5: A graph showing the different site densities $\left(n_{s}\right)$ used to fit the experimental salt-solution titration data with numerical modelling for $\mathrm{Na}$ (blue), $\mathrm{Mg}$ (black) or $\mathrm{Ca}$ (green) and ( $\log _{10}$ of) the equilibrium constant $\left(K^{\text {int }}\right)$ that provides the best fit in each case. The linear relationships observed in this log-log plot lead to Equation 10. 